\title{
MEASURING THE EFFECTIVENESS OF INFLUENCERS' ACTIVITIES
}

\author{
URSZULA CHRĄCHOL-BARCZYK
}

University of Szczecin, Faculty of Management and Economics of Services, Poland

e-mail: urszula.chrachol@wzieu.pl

\begin{tabular}{l|l}
$\begin{array}{l}\text { RECEIVED } \\
\text { JELCEPTED }\end{array}$ & $\begin{array}{l}\text { 18 January } 2018 \\
\text { 2 September } 2018\end{array}$ \\
CLASSIFICATION & L2, L86, M31 \\
KEYWSTRACT & $\begin{array}{l}\text { Kuba Klawiter, who is in Poland one of the most known influencers in the new technologies industry, took part } \\
\text { in the online campaign of x-comput store. After announcing to the subscribers the details of the promotional } \\
\text { campaign dedicated to them, he made the servers block after } 5 \text { minutes. Marketing influencer has been } \\
\text { developing on the Polish market for two years. The purpose of this article is to describe influencerów activities } \\
\text { and to identify examples of indicators that can be used to study the effectiveness of their operations. The article } \\
\text { is based on secondary sources. }\end{array}$
\end{tabular}

\section{Introduction}

Marketing influencer has become an element of the Polish market. More and more companies use such a person in their activities, because they have many advantages and are a relatively new tool on the Polish market. According to the Promosphere study (2016) "Shopping habits of Poles": 78\% of consumers searched online information before making purchase decisions. When searching for information on the web, the seekers encounter 
blogs, forums, opinions, advice, videos, photos - influencers' accounts. However, according to a report by the Polish Association of Bloggers and Vloggers and Hash.fm, for $72 \%$ of readers of blogs and vlogs are the first source of information about products and services - more important than the opinions of family and friends. $60 \%$ of regular customers use them to make informed purchases, and $53 \%$ admit that they made purchases under their influence (Raport..., 2018). That is why the development of marketing influencer is so dynamic. They were the fastest growing tool in 2017 and their development in 2018 is estimated even higher than last year. It works on the basis of influencers, i.e. people who enjoy high popularity and recognition among a group of people. They constitute "authority" in their area to their recipients and have a great influence on the behavior of their observers.

Most often, the reasons for using marketing influencer in the company include (Kotlinski, 2018):

- authenticity - influencers often show their everyday life, which is not stylized and this authenticity translates into the trust and engagement of recipients,

- originality - influencer can in a very unimaginable way warm up the image of a brand, and at the same time affecting the sale,

- inbound - the recipients do not like the sales content, which is currently abundant. That is why recipients should be provided with the content they need and appreciate,

- return on investment - there are many examples on the market showing that well-planned cooperation means immediate sales results and long-lasting image effects,

- fight with adblock, i.e. blocking the viewing of advertisements through various plugins - marketing influencer by product placement eliminates the possibility of blocking advertisements and in addition they are shown where people want to watch them.

\section{Measurability of marketing influencer's effects}

There are currently many tools on the market that measure the effectiveness of influencers' engagement in the company's marketing activities. One of the most well-known indicators used in many marketing activities is $\mathrm{ROI}$ (investment profitability), which shows whether the company received the expected results in relation to the expenditures incurred.

The value of the indicator that can be obtained depends to a large extent on the campaign's goals. If these are very general goals, e.g. increasing brand awareness, the effect of the actions is difficult to measure. The goals that should be set in influencer marketing should be as detailed as possible and refer to the possibilities of a given social media.

The most frequently mentioned indicators are: campaign reach, audience involvement, lead acquisition, sales.

The range of the campaign can be determined by the number of followers, checking how many of them joined a given social media. It is also possible to analyze the traffic on the website, checking how many sites were available after publishing materials related to the company and what source the recipients come from (Cilińdź, 2018).

Customer engagement shows how much the content shown was interesting or valuable to them. This point is also important due to the constantly changing Facebook algorithms, which differentiate the ranges of posts depending on the number and type of user reactions. Commitment is also closely related to the so-called coefficient of involvement, understood as a common denominator for a simple comparison of two influencers. Depending on the number of fans and their interactions, one can make an analysis that was more effective. You can measure the 
coefficient of involvement in several ways - by focusing on posts or on fans. It is important to use the same model throughout the analyzes (Sadowski, 2018).

Google Analytics Demographics is a free tool that allows to analyze whether the sent message or visitors to the company's website are part of the target group that was previously defined and which is the company's priority. Also, thanks to Google Aalytics one can check which medium generated the most traffic on the company's website, so that future marketing activities can be transferred to the medium that is most popular among the company's clients and gain even more leads.

Measurability of influencer's activities is also possible through (Sadowski, 2018):

- the number of purchases made through an affiliate link with the use of a special discount code - this allows to learn the source from which the buyers came, what their average basket value is and what they buy most. In the future, it is possible to check whether these users are returning and making subsequent purchases;

- number of participants/contest - it is worth measuring how many people took part in it,

- media buzz - it is worth checking whether the campaign has translated into the number of entries in which the brand was mentioned, especially when a certain hashtag is promoted during the campaign, or when the actions taken can have a real impact on the amount of content about the brand (e.g. cooperation with influencer, under the influence of which Internet users buy a product can bring an increase in the number of reviews or entries recommending/anti-recommending a product).

Table 1 presents the elements whose increase can constitute the goals of the campaign with the participation of influencers.

Table 1. Measures in influencer marketing

\begin{tabular}{|c|c|c|c|}
\hline Elements of measurement & Branding & Purchase intentions & Direct response \\
\hline 1 & 2 & 3 & 4 \\
\hline \multicolumn{4}{|c|}{ YuoTuBe } \\
\hline Subscribers & $\mathrm{x}$ & & \\
\hline Entries from social media & $x$ & & \\
\hline Views & $x$ & & \\
\hline Likes & $x$ & $x$ & \\
\hline Link clicking & $x$ & $x$ & $x$ \\
\hline Visits & $x$ & $x$ & $x$ \\
\hline Comments & $\mathrm{x}$ & $\mathrm{x}$ & \\
\hline Response & $\mathrm{x}$ & $x$ & $x$ \\
\hline Sharing & $x$ & $x$ & \\
\hline Entries from exit-pop-up & $x$ & & $x$ \\
\hline \multicolumn{4}{|c|}{ WordPress } \\
\hline Entries from social media & $x$ & & \\
\hline Post views & $x$ & & \\
\hline Observers & $x$ & & \\
\hline Comments & $x$ & $x$ & \\
\hline Link clicks & $x$ & $x$ & $x$ \\
\hline Visits & $x$ & $x$ & $x$ \\
\hline Entries from exit-pop-up & $x$ & & $x$ \\
\hline
\end{tabular}




\begin{tabular}{|c|c|c|c|}
\hline 1 & 2 & 3 & 4 \\
\hline \multicolumn{4}{|c|}{ Facebook, Twitter, Instagram } \\
\hline Likes & $x$ & $x$ & \\
\hline Views & $x$ & & \\
\hline Comments & $x$ & $x$ & \\
\hline Sharing & $x$ & $x$ & $x$ \\
\hline Link clicks & $x$ & $x$ & $\mathrm{x}$ \\
\hline Entries from exit-pop-up & $x$ & & $\mathrm{x}$ \\
\hline \multicolumn{4}{|c|}{ Pinterest } \\
\hline Number of repins & $\mathrm{x}$ & $x$ & $\mathrm{x}$ \\
\hline Sharing & $x$ & $x$ & \\
\hline Comments & $\mathrm{x}$ & $x$ & \\
\hline Entries & $x$ & $x$ & $\mathrm{x}$ \\
\hline Close-ups & $x$ & $x$ & $\mathrm{x}$ \\
\hline Observers & $\mathrm{x}$ & & \\
\hline Views & $x$ & & \\
\hline Range & $x$ & & \\
\hline Involvment & $x$ & $x$ & \\
\hline Entries from exit-pop-up & $x$ & & $\mathrm{x}$ \\
\hline
\end{tabular}

Source: Sadowski (2018).

There are also a number of IT tools on the market that are often free and they allow for analyzing various elements of the marketing of the marketing influencer. The most popular include (Głuchowska, 2018):

1. Google Analytics - allows to generate dozens of types of reports on Internet traffic, conversions and ROI.

2. Google Tag Manager - allows to easily work, e.g. with tags, and thanks to that, check where traffic to the website comes from, how users behave and generally monitor any online campaigns without the participation of IT professionals.

3. Campaign URL Builder - allows to check where the users have come from (utm_source), how they came, from what medium (utm_medium) and from what campaign (utm_campaign).

4. Piwik - allows to analyze access to the website and traffic on the WWW. It differs from Google Analytics with the fact that data is stored locally, so one can have full control over it.

5. Branch Metrics - allows to create deep links to online campaigns and conduct business analysis, i.e. in terms of conversion, $\mathrm{ROI}$ or user involvement.

6. Bitly - similarly to Campaign URL Builder and Branch, it allows to track the behavior of users clicking on a link, although it is often associated only with shortening of links.

7. Brand24 - the most popular tool used by marketers to track records in the network and social media about their own brands and other interesting keywords.

8. Internal statistics of social networks (Facebook, Instagram, Twitter, Linkedln) - thanks to reports from social media statistics, the influencer can be asked for, one can see how engaging for the fans published content associated with the brand was.

9. Iconosquare - allows to get detailed statistics on specific accounts from Instagram and Facebook, allowing to monitor their subscribers.

10. Cyfe- allows to create a personalized panel to collect statistical data from various sources in one place. 
11. Socialmention - a simple search engine for social media and blogs that will quickly find content on a specific topic, including the brand promoted by influencer.

12. Mention - a tool to monitor the Internet in real time, it analyzes the actions of competitors, searches for influencers, discovers consumer insight, i.e. the needs of recipients.

\section{Conclusions}

In the case of influencer marketing, as in any other marketing area, it is very important to regularly measure the results achieved. All analytical tools related to marketing activities or social media only will show values regarding the engagement of message recipients, reaching a specific group of messages, while from the point of view of the company's functioning, it is important to translate this data into the sale of a product or service.

One should not limit their activity to trusting or believing that someone will view, comment or share content and bring a favorable response. Implementation of measures that show what the return on investment was is crucial. The measures will allow for comparison of subsequent actions with influencers and will allow for deciding if they were valuable or not. Whether the social media channel is good for the brand or whether we reached the right opinion leaders? However, such an assessment is not simple. It is often difficult to indicate which component of influencer marketing translated into sales growth. It does not mean that it is impossible. If we use professional tools, it will turn out that the expenses for the promotion brought the expected returns. This was proved by Tomoson study conducted on 125 marketers. The answer to the question, what was the ROI in your campaign using influencers, showed that, on average, for each dollar invested there was an impressive $\$ 6.5$ return. $70 \%$ of respondents had a return of $\$ 2$ or more. The best reached as much as $\$ 20$. (Raport..., 2018).

These results clearly show that through properly selecting influencers for the company's needs it is possible to achieve very good results for little money. Such examples of successfully carried out activities are also frequent on the Polish market.

\section{References}

Cilińdź, D. (2018). Jak mierzyć skuteczność kampanii influencer marketingu? Retrieved from: http://sasdesign.pl/ mierzyc-skutecznosc-kampanii-influencer-marketingu.

Głuchowska, Ż. (2018). Narzędzia do mierzenia efektów influencer marketingu. Retrieved from: https://www.whitepress.pl/ baza-wiedzy/570/narzedzia-do-mierzenia-efektow-influencer-marketingu.

Kotliński, D. (2018). Dlaczego influencer marketing jest skuteczny? Retrieved from: http://adnext.pl/3109-2.

Raport. Analityka i monitoring influencerów (2018). Newspoint. Retrieved from: https://www.newspoint.pl/Analityka-i-monitoringinfluencerow-Raport-Newspoint.pdf.

Sadowski, R. (2018). Influencer marketing można mierzyć. Retrieved from: https://prowly.com/magazine/2018/03/07/ influencer-marketing-moz\%CC\%87na-mierzyc.

Cite this article aS: Chrąchol-Barczyk, U. (2018). Measuring the effectiveness of influencers' activities. European Journal of Service Management, 3 (27/2), 79-83. DOI: 10.18276/ejsm.2018.27/2-10. 